\title{
Potential Utilization of Low Quality Sweet Potato for Bioethanol Production by Saccharomyces cerevisiae TISTR5339
}

\author{
Supasit CHOOKLIN ${ }^{1, *}$, Parichat NINUP-PATHAM² and Saovanee CHOOJIT ${ }^{3}$ \\ ${ }^{1}$ Department of Food Science and Technology, Faculty of Agro-Industry, \\ Rajamangala University of Technology Srivijaya, Thungyai, Nakhon Si Thamarat 80240, Thailand \\ ${ }^{2}$ Department of Biotechnology, Faculty of Agro-Industry, \\ Rajamangala University of Technology Srivijaya, Thungyai, Nakhon Si Thamarat 80240, Thailand \\ ${ }^{3}$ Department of General Science, Faculty of Science and Technology, \\ Muban Chombueng Rajabhat University, Chom Bueng, Ratchaburi 70150, Thailand
}

("Corresponding author’s e-mail: supasit_c@yahoo.co.th, supasit.c2015@gmail.com)

Received: 25 May 2018, Revised: 12 November 2018, Accepted: 13 December 2018

\begin{abstract}
This study was aimed to investigate the optimal condition of ethanol production that has 2 major stages: acid hydrolysis and fermentation processes. These processes came from low quality sweet potato (LQSP) which was destroyed by the sweet potato weevil. The main compositions of LQSP were starch and fiber which consist of 55.25 and $10.29 \%$, respectively. In this case, the starch can be hydrolyzed to reduce the sugar, followed by the fermentation of the reduced sugar to ethanol. For this experiment, the effecting factors on acid hydrolysis of LQSP and the ethanol fermentation condition were optimized by $S$. cerevisiae using Response Surface Methodology (RSM) with Box-Behnken design in order to maximize ethanol yield. It was found that the maximum reducing sugar concentration of $390.99 \pm 5.35 \mathrm{~g} / \mathrm{L}$ was obtained from the hydrolysis condition with $1 \%(\mathrm{v} / \mathrm{v})$ of sulfuric acid and $25 \%(\mathrm{w} / \mathrm{v})$ of LQSP. Accordingly, the effects of ammonium sulphate content $(0.05-0.15 \%), \mathrm{pH}(4.5-5.5)$ and inoculum content $(5-10 \%)$ on ethanol production was determined by RSM using Box-Behnken experiment design with a total 17 sets of all trials. The results were found that the maximum experimental ethanol productivity of $5.98 \mathrm{~g} / \mathrm{L}$ was obtained from the condition at $0.05 \%$ of ammonium sulphate, $\mathrm{pH} 5.5$ and $5.0 \%$ of inoculum size to $90 \mathrm{~mL}$ LQSP based medium and incubated at $30{ }^{\circ} \mathrm{C}$ for $48 \mathrm{~h}$. In addition, the scale-up of ethanol production was studied in $9 \mathrm{~L}$ fermenter which provided the maximum ethanol yield of $5.04 \mathrm{~g} / \mathrm{L}$. Therefore, it can be concluded that LQSP had a potential as a substrate for ethanol production.
\end{abstract}

Keywords: Low quality sweet potato, Acid hydrolysis, Ethanol, Saccharomyces cerevisiae, Response surface methodology

\section{Introduction}

Renewable and sustainable energy resources play a crucial role in the future of human life. As the demand for the limited global supply of non-renewable energy resources increases, the price of oil and natural gas also increases. Bioethanol is one of the most promising biofuels from renewable resources, since it has been blended with gasoline into gasohol to make E20 and E85 [1]. It has become an alternative renewable and sustainable energy source, which can be produced from agricultural crops or lignocellulosic biomass [2]. Most bioethanol production throughout the world, including Thailand that has a lot of resources of sugar and starch crops such as sugarcane and corn as sugar/starch based feedstocks are currently predominant at the industrial level. Such a production of bioethanol are 
http://wu.ac.th

economically feasible. However, there are raising questions concerning the competition between food supply and arable land [3]. Thus, there is a growing interest to find alternative bioresources other than sugarcane/beet molassess and starchy crops such as cassava, sweet potato, and sweet sourghum for ethanol production [2].

Sweet potato (Ipomoea batatas L.) has been considered a promising substrate for the production of ethanol through fermentation since it has a higher starch yield per unit than grains [4]. Moreover, its average yielded carbohydrate is higher than cassava and corn, up to $80 \%$. This has greater potential as ethanol source [5]. Sweet potato is cheap, readily available in the local market, and offers ease in product processing. It contains starch $(178 \mathrm{~g} / \mathrm{kg})$, total sugars $(26 \mathrm{~g} / \mathrm{kg})$ and protein $(3.2 \mathrm{~g} / \mathrm{kg})$ on fresh weight basis. The starch can be hydrolyzed to monomer units of carbohydrates and can be used by the microorganisms in fermentation process [6]. Industrial sweet potatoes are not intended for use as a food crop. They are bred to increase its starch content, significantly reducing its attractiveness as a food crop when compared to other conventional food cultivars. Therefore, they offer potentially greater fermentable sugar yields for industrial conversion processes, which implies an opportunity for an increase in planted acreage [4]. It has been reported that some industrial sweet potatoes breeding lines developed could produce ethanol yields of 4,500 - 6,500 L/ha compared to 2,800 - 3,800 L/ha for corn [7].

The ethanol production process from starch has 2 major stages: hydrolysis of carbohydrate to produce fermentable sugars and fermentation of reducing sugars to ethanol [8]. Therefore, efficiency and cost-effectiveness of hydrolysis and fermentation are needed to maximize the reduction of sugar concentration and ethanol productivities [9]. In addition, the dilute acids have been successfully used in the hydrolysis of a wide range of feed stocks, ranging from hardwoods to grasses and agricultural residues. Furthermore, sulfuric acid $\left(\mathrm{H}_{2} \mathrm{SO}_{4}\right)$ at low concentrations, has been widely studied because it is inexpensive, effective with low acid consumption, and gives high conversion of starch/cellulose to glucose [10,11]. While Baker's yeast Saccharomyces cerevisiae has been traditionally used in the brewing industry to produce ethanol from hexoses, it is one of the most importance microorganisms which is being widely used for the conversion of sugar to ethanol due to its high ethanol yield, high tolerance to ethanol concentration, high selectivity, low accumulation of by-products, high fermentation rate, good tolerance to substrate concentration and lower $\mathrm{pH}$ value [12].

Moreover, Response surface methodology (RSM) is a statistical and mathematical tool for designing experiments, building models, and searching for their optimal set-point for desirable response while reducing the number of required experiments [13]. The optimizing processes are based on the fit of a polynomial equation to the experimental data, which must describe the behavior of a data set with the objective of making statistical predictions. Moreover, it can be applied successfully when a response or a set of responses of interest are influenced by several variables [14].

Therefore, this study aimed to investigate the factors that affected the acid hydrolysis of LQSP and the optimization of the ethanol fermentation condition by $S$. cerevisiae using RSM with Box-Behnken design in order to maximize ethanol yield.

\section{Materials and methods}

\section{Low quality sweet potato}

The low quality sweet potato (LQSP) that was destroyed by sweet potato weevil was collected. The physical characteristics of the LQSP is mushy, shrivel, and its peel turns brown or black as shown in Figure 1. These LQSPs were supplied by the local sweet potato planting area in Nakhon Si Thammarat Province, Thailand. 

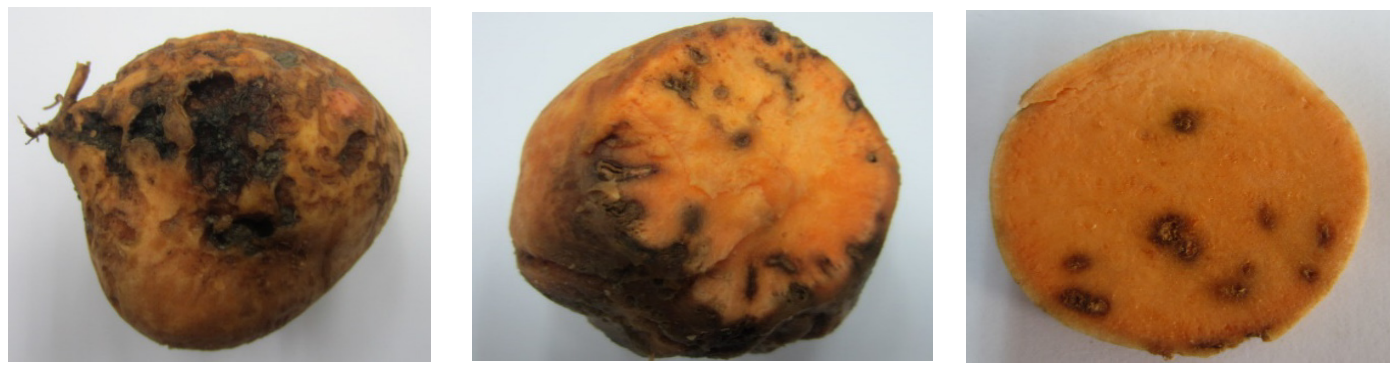

Figure 1 The physical characteristics of Low quality sweet potato (LQSP).

\section{Microorganism and culture conditions}

S. cerevisiae TISTR 5339 was provided from the Culture Collection of the Microbiological Resources Center, Thailand Institute of Scientific and Technology Research (TISTR), Pathum Thani, Thailand. The culture of $S$. cerevisiae was maintained on YM agar slants (consisting of glucose, 20; yeast extract, 3; malt extract, 3; peptone, 5; and agar 15, all in $\mathrm{g} / \mathrm{L}$ ) at $4{ }^{\circ} \mathrm{C}$. An inoculum was prepared by transferring a loopful of cells to $50 \mathrm{~mL}$ of YM medium broth, which was incubated and grown at $30 \pm 2$ ${ }^{\circ} \mathrm{C}$ on a shaker at $150 \mathrm{rpm}$ before inoculating the reactor.

\section{Experimental methods}

\section{LQSP preparation and composition analysis}

LQSP samples were washed thoroughly to remove the dust and other debris, then peeled off and chopped into small pieces. After that, the LQSP pieces were dried in the oven at $55^{\circ} \mathrm{C}$ for $24 \mathrm{~h}$ till the moisture content reduced to $8 \%$ and grinded with mixture grinder into powder. Next, the LQSP grinded powder was sieved through a steel mesh to get $0.5 \mathrm{~mm}^{3}$ diameter size and stored in aluminium foil bag for further use. Finally, the LQSP compositions were analyzed according to AOAC methods [15].

\section{Acid hydrolysis of LQSP powder}

The diluted sulfuric acid $\left(\mathrm{H}_{2} \mathrm{SO}_{4}\right)$ hydrolysis of LQSP powder was operated in $250 \mathrm{~mL}$ round bottles. LQSP powder was used in various amounts to get the optimum ratio of sample to acid $(5,15$ and $25 \% \mathrm{w} / \mathrm{v})$, in $100 \mathrm{~mL} \mathrm{H}_{2} \mathrm{SO}_{4}$ which varied concentrations $(1,3$ and $5 \% \mathrm{v} / \mathrm{v})$. Then, the suspension was performed in an autoclave at $121^{\circ} \mathrm{C}, 15 \mathrm{psi}$ for $30 \mathrm{~min}$. After hydrolysis, the solid residue was separated from the diluted $\mathrm{H}_{2} \mathrm{SO}_{4}$ solution by using vacuum filtration with Whatman filter paper No. 4 and the filtrated solution from each experiments were collected and analyzed to determine the reducing sugar [16] and total sugar contents [17].

\section{Optimization of fermentation variables using RSM}

RSM is a collection of mathematical and statistical techniques based on the fit of a polynomial equation to the experimental data, which must describe the behavior of a data set with the objective of making statistical previsions. It can be well applied when a response or a set of responses of interest are influenced by several variables. Herein, Box-Behnken design is one of the most commonly used response surface designs to study the effects of variables on the response, and subsequently in optimization studies [14].

We expected that under optimum acid hydrolysis conditions of LQSP powder, there was a provided maximum glucose for ethanol fermentation by $S$. cerevisiae. In this study, the Optimization of ethanol production from LQSP powder was evaluated by using the Design expert software (Trial version 11.0, 
http://wu.ac.th

Stat-Ease, Inc., Minneapolis, USA). $10 \% \mathrm{v} / \mathrm{v}$ of inoculum size was transferred into a $250 \mathrm{~mL}$ Erlenmeyer flasks containing $90 \mathrm{~mL}$ of LQSP based culture medium and was subsequently incubated at $30 \pm 2{ }^{\circ} \mathrm{C}$ for $48 \mathrm{~h}$ in triplicates. Samples were harvested at $48 \mathrm{~h}$ of fermentation to monitor ethanol productivity. Three independent variables, namely ammonium sulphate concentration $(\mathrm{A}, 0.05,0.1$ and $0.15 \% \mathrm{w} / \mathrm{v}), \mathrm{pH}(\mathrm{B}$, 4.5, 5.0 and 5.5) and inoculum size $(\mathrm{C}, 5,7.5$ and $10 \% \mathrm{w} / \mathrm{v})$ were used at 3 coded levels $(-1,0,+1)$, while the summarization of the range and levels of the variables was investigated with low, middle, and high levels of each variable. This is included as one of the 17 experimental designs shown in Table $\mathbf{1}$.

Table 1 Experimental range and levels of the independent variables on the fermentation of LQSP.

\begin{tabular}{lcccc}
\hline \multirow{2}{*}{ Variables } & \multirow{2}{*}{ Symbols } & \multicolumn{3}{c}{ Coded levels } \\
\cline { 3 - 5 } & & $\mathbf{- 1}$ & $\mathbf{0}$ & $\mathbf{+ 1}$ \\
\hline Ammonium sulphate & $\mathrm{A}$ & 0.05 & 0.1 & 0.15 \\
$\mathrm{pH}$ & $\mathrm{B}$ & 4.5 & 5.0 & 5.5 \\
Inoculum size & $\mathrm{C}$ & 5 & 7.5 & 10 \\
\hline
\end{tabular}

The significance of each variable, interactions, and fitting factors are based on the following $2^{\text {nd }}$ order polynomial that coded according to Eq. (1);

$$
Y_{i}=\beta_{0}+\beta_{1} A+\beta_{2} B+\beta_{3} C+\beta_{11} A^{2}+\beta_{22} B^{2}+\beta_{33} C^{2}+\beta_{12} A B+\beta_{13} A C+\beta_{23} B C
$$

where $Y_{i}$ is the predicted response (ethanol content), $\beta_{0}$ is the intercept coefficient, $\beta_{1}, \beta_{2}, \beta_{3}$ are the linear coefficient, $\beta_{11}, \beta_{22}, \beta_{33}$ are the quadratic coefficients, $\beta_{12}, \beta_{13}, \beta_{23}$ are the cross-product coefficients and $\mathrm{A}, \mathrm{B}, \mathrm{C}$ are the independent variables studied.

\section{Model fitting and statistical analysis}

All fermentation experiments were carried out in triplicate and results expressed as mean values. The results obtained from Box-Behnken Design were used to determine the regression coefficients of the $2^{\text {nd }}$ order multi-regression model. The analysis of variance (ANOVA) was evaluated using Design-Expert 11.0. The quality of the fit of the polynomial model equation was assessed by determining the $R^{2}$ coefficient; its statistical and regression coefficient significance were checked with $F$-test and $P$-value, respectively. Three dimensional (3D) surface plot and corresponding contour plots were drawn to illustrate the effect of the independent variables on the response (ethanol content). Finally, the optimum values for the selected variables were obtained by solving the regression equation.

\section{Analytical methods}

The reduction of sugar was measured by dinitrosalicylic colorimetric method (DNS). The standard glucose stock solution $10 \mathrm{~g} / \mathrm{L}$ was prepared by dissolving $0.20 \mathrm{~g}$ of D-(+)-Glucose anhydrous $\left(\mathrm{C}_{6} \mathrm{H}_{12} \mathrm{O}_{6}\right)$ in $20 \mathrm{~mL}$ of DI water. Working solutions were daily prepared by appropriate dilution of the stock solution in DI water. After that 3,5-dinitrosalicylic acid reagent was prepared by dissolving $1 \mathrm{~g}$ of 3,5dinitrosalicylic acid in $20 \mathrm{~mL}$ of $2 \mathrm{M} \mathrm{NaOH}$. It was then mixed with potassium sodium tartrate $\left(\mathrm{C}_{4} \mathrm{H}_{4} \mathrm{KNaO}_{6}\right)$ solution $\left(30 \mathrm{~g}\right.$ of $\mathrm{C}_{4} \mathrm{H}_{4} \mathrm{KNaO}_{6}$ in $50 \mathrm{~mL}$ of DI water) on a magnetic stirrer hot plate and diluted to $100 \mathrm{~mL}$ with DI water. Finally, Calibration curve for estimation of reducing sugar yield was obtained by plotting the absorbance (at $520 \mathrm{~nm}$ ) vs. concentrations of standard glucose in the range of $0.20-1.00 \mathrm{~g} / \mathrm{L}$. The concentrations of glucose were daily prepared by dilution of the stock solution $(\mathrm{y}=$ $\left.1.0303 \mathrm{x}+0.0225 ; R^{2}=0.995\right)[16]$.

Total sugar was measured by phenol-sulphuric method. Standard curve of sugar was prepared using the serial concentration of glucose solution $(10-100 \mu \mathrm{g} / \mathrm{mL})$ in DI water. The $1 \mathrm{~mL}$ of each 
http://wu.ac.th

concentration was transferred to test tube and added with $1 \mathrm{~mL}$ of $5 \%$ phenol solution. The mixtures were shaken and followed by the addition of $5 \mathrm{~mL}$ conc. sulphuric acid. All mixtures were homogenized by vortex and stand for $10 \mathrm{~min}$. The absorbance $(488 \mathrm{~nm})$ of the reaction mixture was measured. Finally, the relation between absorbance and glucose concentration was plotted $\left(\mathrm{y}=0.0094 \times-0.0207 ; R^{2}=0.993\right)$ [17].

Ethanol content was measured by flash distillation method. The $1 \mathrm{~mL}$ of diluted sample was transferred to screw cape tube and added with $2 \mathrm{~mL}$ of $0.1 \mathrm{M}$ potassium dichromate in $0.5 \mathrm{M}$ sulphuric acid. After that, DI water was added and the screw cape tube was closed. It was boiled for 5 min and cooled in ice water immediately. Finally, the relation between absorbance and ethanol concentration was plotted $\left(\mathrm{y}=0.0309 \mathrm{x} ; R^{2}=0.991\right)[18]$.

\section{Results and discussions}

\section{LQSP compositions}

To identify the compositions of the LQSP powder before acid hydrolysis, there were moisture, starch, protein, fat, ash and fiber contents which were analysed according to the standard AOAC methods [15]. The chemical compositions of LQSP powder are listed in Table 2. The main compositions were starch and fiber that consist of 55.25 and $10.29 \%$, respectively. Moreover, the composition of LQSP was as same as fresh sweet potato (FSP) that reported by $[19,20]$. Therefore, LQSP is suitable to use as raw material for ethanol production.

Table 2 LQSP compositions.

\begin{tabular}{lcccccc}
\hline Type & $\begin{array}{c}\text { Moisture } \\
(\mathbf{\%})\end{array}$ & $\begin{array}{c}\text { Protein } \\
(\mathbf{\%})\end{array}$ & $\begin{array}{c}\text { Fat } \\
\mathbf{( \% )}\end{array}$ & $\begin{array}{c}\text { Ash } \\
(\mathbf{\%})\end{array}$ & $\begin{array}{c}\text { Fiber } \\
(\mathbf{\%})\end{array}$ & $\begin{array}{c}\text { Starch } \\
(\%)\end{array}$ \\
\hline LQSP & $7.35 \pm 1.61$ & $3.89 \pm 0.16$ & $1.34 \pm 0.21$ & $3.94 \pm 0.03$ & $10.29 \pm 2.16$ & $55.25 \pm 5.37$ \\
FSP $^{1}$ & $7.34 \pm 0.77$ & $3.31 \pm 0.42$ & $0.29 \pm 0.08$ & - & - & $51.89 \pm 8.97$ \\
FSP $^{2}$ & $8.06 \pm 1.13$ & & & & $55.76 \pm 6.82$ \\
\hline
\end{tabular}

${ }^{1}$ Fresh sweet potato, $[19] ;{ }^{2}[20]$

Acid hydrolysis of LQSP powder

LQSP is a starchy material and needs to be hydrolyzed before fermentation by following this flowchart.

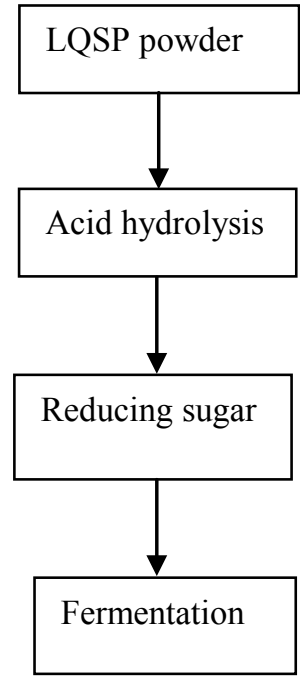


http://wu.ac.th

From Table 2, it was found that the main LQSP composition was starch; therefore, hydrolysis was needed before the fermentation of starchy material. Starch is a polysaccharide comprising of glucose monomers linked by alpha - glycosidic bonds [21]. Acid hydrolysis actually will break down the starch molecules at random and sugar is mainly produced. The acid disrupts the hydrogen bonding between starch chains, converting it to a completely amorphous state, thereby forming a homogenous gelatin [22]. Starch hydrolysis is expressed as;

$$
\begin{array}{cr}
\left(\mathrm{C}_{6} \mathrm{H}_{10} \mathrm{O}_{5}\right)_{\mathrm{n}} & +\mathrm{nH} 2 \mathrm{O}=\mathrm{nC}_{6} \mathrm{H}_{12} \mathrm{O}_{6} \\
\text { Starch } & \text { D - glucose }
\end{array}
$$

The effected parameters for acid hydrolysis of LQSP via LQSP powder to acid and $\mathrm{H}_{2} \mathrm{SO}_{4}$ concentrations were investigated and evaluated in order to obtain the maximum reducing sugar concentration of LQSP. This was, then sequentially utilized for ethanol fermentation. It was found that the maximum reducing sugar concentration of $390.99 \pm 5.35 \mathrm{~g} / \mathrm{L}$ was obtained in the hydrolysis condition with $1 \%(\mathrm{v} / \mathrm{v})$ of sulfuric acid and $25 \%(\mathrm{w} / \mathrm{v})$ of LQSP. The effect of acid concentrations and LQSP starch concentration on reducing sugar and total sugar concentrations after acid hydrolysis of LQSP can be seen in Figure 2. It was found that increasing acid concentration caused to decrease reducing sugar and total sugar concentrations. Research by [23] studied the glucose production from hydrolysate pineapple residue. It was found that reducing sugar can be decreased in an increasing sulfuric concentration. Yoonan et al. [24] demonstrated that optimal \% carbohydrate conversion could be obtained at $60.74 \%$ from hydrolysis at $135{ }^{\circ} \mathrm{C}$ for $90 \mathrm{~min}$ with $0.1 \mathrm{M}$ sulfuric acid. Increasing the acid concentration resulted in marginal improvements in cassava peel conversion with sulfuric acid, and a decrease of about $16 \%$ when the acid level was raised more than $0.1 \mathrm{M}$. At the higher acid concentration, a dark colored hydrolysate, along with conversion by-products, was observed, thus suggesting sugars degradation. Maxwell et al. [25] reported the highest reducing sugar yield obtained in this study condition of $3 \mathrm{~g}$ of sweet potato peels hydrolyzed with $0.6 \mathrm{M}$ sulphuric acid at $30{ }^{\circ} \mathrm{C}$ for $16 \mathrm{~h}$ is $0.141 \mathrm{~g} / 100 \mathrm{~mL}$. Above $0.6 \mathrm{M}$ acid concentration, it was observed that the monomer sugar yields decreased as the acid concentration increased. This could be due to the degradation of product monomers.

Moreover, these results were in agreement with the results obtained by research [26] found that the decreasing trends in the reducing sugar at too high acid concentration are due to the occurrence of the decomposition of sugars to form inhibitory compounds such as hydroxymethylfurfural, furfural, levulinic acid and acetic acid. Moreover, this study found that reducing sugar and total sugar increased remarkably with increasing LQSP starch concentration and the conversion of 5, 15 and $25 \% \mathrm{w} / \mathrm{v}$ LQSP with $1 \% \mathrm{v} / \mathrm{v}$ sulfuric acid was 37.30, 69.39 and $69.99 \%$, respectively (data not showed). 
http://wu.ac.th

a)

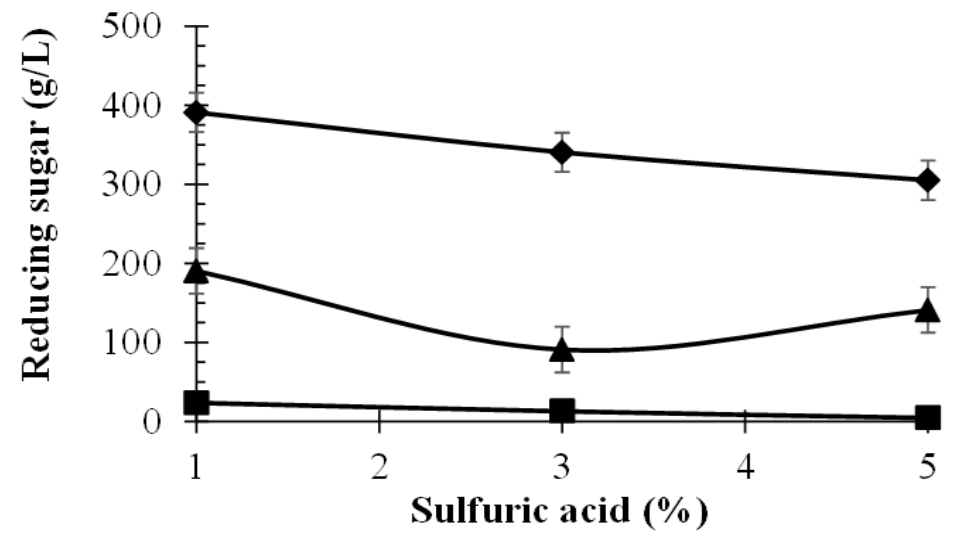

b)

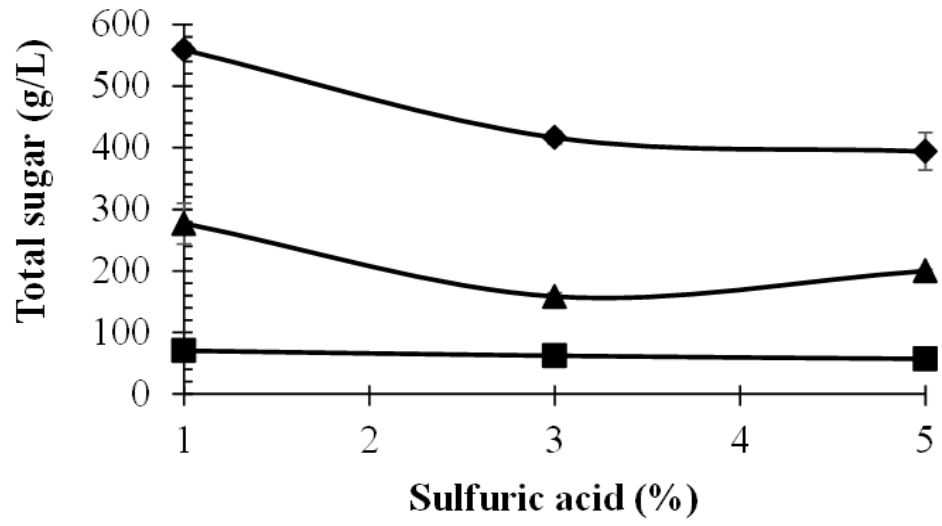

$\rightarrow$ starch $5 \mathrm{~g} \rightarrow$ starch $15 \mathrm{~g} \multimap-\operatorname{starch} 25 \mathrm{~g}$

Figure 2 Effects of various acid concentrations and ratio of sample to acid on (a) reducing sugar and (b) total sugar after acid hydrolysis of LQSP.

RSM optimization of the fermentation conditions

The Box-Behnken experiment design led to a total 17 sets of experiments. The low, middle, and high levels of each variable and the experimental design and respective experimental results are given in Table 3. The maximum experimental ethanol production of $5.98 \mathrm{~g} / \mathrm{L}$ was obtained with $0.05 \%$ of ammonium sulphate, $\mathrm{pH} 5.5$ and $5.0 \%$ of inoculum size (Trial 2). 
http://wu.ac.th

Table 3 Experimental range and levels of the 3 independent variables used in RSM with terms of coded, actual factors and the ethanol production results from each experimental trial for the 3 factor with response surface analysis.

\begin{tabular}{ccccc}
\hline \multirow{2}{*}{ Trial } & \multicolumn{3}{c}{ Independent variables } & \multirow{2}{*}{ Ethanol (g/L) } \\
\cline { 2 - 4 } & Ammonium sulphate $(\% \mathbf{\%} / \mathbf{v})$ & $\mathbf{p H}$ & Inoculum size $\mathbf{( \% \mathbf { v } / \mathbf { v } )}$ & 4.18 \\
\hline 1 & $-1(0.05)$ & $1(5.5)$ & $0(7.5)$ & 5.98 \\
2 & $-1(0.05)$ & $1(5.5)$ & $0(5.0)$ & 5.49 \\
3 & $1(0.15)$ & $1(5.5)$ & $0(7.5)$ & 1.85 \\
4 & $1(0.15)$ & $-1(4.5)$ & $0(7.5)$ & 2.27 \\
5 & $0(0.10)$ & $1(5.0)$ & $0(7.5)$ & 0.56 \\
6 & $0(0.10)$ & $-1(4.5)$ & $-1(5.0)$ & 2.53 \\
7 & $0(0.10)$ & $1(5.0)$ & $0(7.5)$ & 3.13 \\
8 & $0(0.05)$ & $1(5.0)$ & $-1(5.0)$ & 3.84 \\
9 & $0(0.10)$ & $0(5.0)$ & $0(7.5)$ & 1.42 \\
10 & $-1(0.05)$ & $0(4.5)$ & $0(7.5)$ & 2.64 \\
11 & $-1(0.10)$ & $-1(4.5)$ & $1(10)$ & 1.99 \\
12 & $0(0.10)$ & $0(5.0)$ & $0(7.5)$ & 3.96 \\
13 & $0(0.05)$ & $0(5.0)$ & $1(10)$ & 2.84 \\
14 & $1(0.15)$ & $0(5.0)$ & $1(10)$ & 3.84 \\
15 & $0(0.10)$ & $0(5.0)$ & $0(7.5)$ & 4.84 \\
16 & $1(0.15)$ & $0(5.0)$ & $-1(5.0)$ & 3.98 \\
17 & $0(0.10)$ & $1(5.5)$ & $1(10)$ & \\
\hline
\end{tabular}

Table 4 Regression of coefficients and analysis of variance of the $2^{\text {nd }}$ order polynomial using quadratic model for response variables.

\begin{tabular}{lcccc}
\hline \multicolumn{1}{c}{ Term } & SS & DF & $\boldsymbol{F}$ value & $\boldsymbol{p}$-value \\
\hline A-Ammonium sulphate & 0.0351 & 9 & 0.0453 & 0.8408 \\
B-pH & 21.65 & 1 & 26.79 & $0.0013^{*}$ \\
C-Inoculum size & 0.0630 & 1 & 0.0780 & 0.7881 \\
AB & 0.2116 & 1 & 0.2618 & 0.6246 \\
AC & 2.00 & 1 & 2.48 & 0.1595 \\
BC & 1.30 & 1 & 1.6100 & 0.2453 \\
$\mathrm{~A}^{2}$ & 2.84 & 1 & 3.5200 & 0.1028 \\
$\mathrm{~B}^{2}$ & 0.0040 & 1 & 0.0049 & 0.9460 \\
$\mathrm{C}^{2}$ & 0.0023 & 1 & 0.0028 & 0.9592 \\
Residual & 5.66 & 7 & & \\
Lack of Fit & 2.53 & 3 & 1.08 & 0.4534 \\
Pure Error & 3.13 & 4 & & \\
Core Total & 33.76 & 16 & & \\
\hline
\end{tabular}

$R^{2}=0.8325 ;$ Predicted $R^{2}=0.8318 ; C V(\%)=27.64 ;$ Adequate Precision $=22.49 ;$ SS, Sum of squares; $D F$, degrees of freedom, ${ }^{*}$ Significant at $<0.01$. 
http://wu.ac.th

\section{Model fitting and statistical analysis}

The $2^{\text {nd }}$ order regression fit to the experimental data. The following $2^{\text {nd }}$ order polynomial model describes the ethanol production from LQSP-reducing sugar concentration following by Eq. (2);

$$
\begin{aligned}
\mathrm{Y}= & 2.89+0.0677 \mathrm{~A}+1.65 \mathrm{~B}+0.0891 \mathrm{C}+0.8189 \mathrm{~A}^{2}-0.0292 \mathrm{~B}^{2}-0.0221 \mathrm{C}^{2}-0.2281 \mathrm{AB}-0.7056 \mathrm{AC}- \\
& 0.5702 \mathrm{BC}
\end{aligned}
$$

Here $\mathrm{A}, \mathrm{B}$ and $\mathrm{C}$ are ammonium sulphate, $\mathrm{pH}$, and inoculum size, respectively. The models fitted satisfactorily with the experimental data as indicated by their goodness of fit expressed by $R^{2}$ and $P$ values.

The significance and effects of each variable on ethanol production from LQSP-reducing sugar are presented in Table 4. The value of $R^{2}=0.8325$. This indicated that $83 \%$ of the variations in ammonium sulphate, $\mathrm{pH}$, and inoculum can be explained by this equation. Furthermore, it has only $16.75 \%$ of the total variation which is not explained by the model. Thus, the correlation of experimental and fitted values is accepted. The predicted determination coefficient $R_{\text {Pred }}^{2}=0.8318$ points to the good agreement of the experimental and the predicted values for ethanol production. The coefficient of variation $(\mathrm{CV})$ value indicates the degree of precision with which the experiments are compared. The lower reliability of the experiment is usually indicated by a higher value of $C V(>15)$. In the present case, acceptable $C V$ values were observed for the model of ethanol production (27.64). This denotes that the experiments performed were reliable. The lack of fit measures means the failure of the model to represent the experimental data. Therefore, the lack of fit of regression Eq. (2) is not significant $(P=0.4534)$. This indicates that the model equation was adequate for experimental data on the ethanol production. In this study, $\mathrm{pH}$ (B) was highly significant in their individual effect. Representative response surface plots are shown in Figures 3(a) - 3(c).

Response surface was generated by plotting the response (ethanol production) on the y-axis against any 2 independent variables on the x-axis, while keeping the other independent variables at zero level. The effects of variables and their interactions on reducing sugar yield are described by the 3D response surface plots and 2D contour plots. Therefore, 3 response surfaces were obtained by considering the possible combination. Figures 3(a) - 3(c) represents the 3-dimensional surface plots for the optimization conditions. The plot illustrates the main and the interactive effect of the independent variables on the dependent ones. The response surface plots were generated by plotting the response on the y-axis. In Figure 3a, the interaction plot of $\mathrm{pH}$ and ammonium sulfate concentration shows that the ethanol production increased remarkably with $\mathrm{pH}$ and ammonium sulfate concentration. On the other hand, the ethanol production increased with the increase of an ammonium sulfate concentration. However, the inoculum decreased in size (Figure 3b). The decreasing level of inoculum size and the increasing level of $\mathrm{pH}$, causes to increase in ethanol production (Figure 3c). The research conducted by [27] which reported the effect of inoculum size and $\mathrm{pH}$ found that ethanol productivity by baker yeast decreased as yeast concentration increased from 3 to 4 and $5 \mathrm{~g} / \mathrm{L}$ in coffee husk based substrate. Moreover, the effect of different sunflower head waste inoculum size viz., 2, 4, 6, 8 and $10 \%$ on the ethanol production from unspecialized juice of sweet sorghum obtained a maximum alcohol concentration of 12.45 and $12.23 \%$ $(\mathrm{v} / \mathrm{v})$ at inoculum sizes of 6 and $2 \%$, respectively. $\mathrm{pH}$ is one of the important factors that affect the bioethanol production through SHF (separate hydrolysis and fermentation). The rate of ethanol production by yeast cells is highly affected by the $\mathrm{pH}$ of the fermentation medium. The acidic condition hinders the growth of harmful bacteria and enhances yeast growth. However, more acidic and basic conditions retard the yeast metabolic pathways and the growth of the cells. So, optimum $\mathrm{pH}$ is required for growth of the yeast and ethanol yield. When the $\mathrm{pH}$ was lower than 4.0, the incubation time for maximum ethanol concentration was prolonged and the maximum concentration was not very low. When the $\mathrm{pH}$ value was above 5.0, the quantity of ethanol produced substantially decreased. Therefore, a $\mathrm{pH}$ range of 4.0 - 5.0 may be regarded as the operational limit for the anaerobic ethanol production process. Previous studies showed that high ethanol production was obtained using $\mathrm{pH}$ of 5.0 to 6.0. It was also shown that no ethanol production exists lower than $\mathrm{pH}$ of 4.0 . Optimum $\mathrm{pH}$ for $S$. cerevisiae BY4742 was 
http://wu.ac.th

in the range of 4.0 - 5.0. The mutual interactions of the factors can also be assessed from contour plots. There are some studies that reported on the optimization of ethanol production from sweet potato. For example, the study by [28] reported on ethanol production from sweet potato flour using co-culture of Trichoderma sp. and $S$. cerevisiae in solid-state fermentation which was composed of ammonium sulphate $0.2 \%, \mathrm{pH} \mathrm{5.0}$, inoculated with $10 \%$ inoculum size at $30{ }^{\circ} \mathrm{C}$ for $72 \mathrm{~h}$ with highest ethanol concentration, maximum ethanol productivity $(2.8 \mathrm{~g} / \mathrm{kg}$ substrate $/ \mathrm{h})$, microbial biomass $\left(2.3 \times 10^{9} \mathrm{CFU} / \mathrm{g}\right.$ substrate), ethanol yield (47 g/100g sugar consumed). While the study by [29] reported the ethanol production from sweet potato by $S$. cerevisiae and investigated the effect of inoculum size, temperature, $\mathrm{pH}$ and nitrogen in nutrient, they found that the maximum ethanol was $7.59 \%(\mathrm{v} / \mathrm{v})$ which was obtained with $10 \%$ inoculum size, peptone $1.5 \mathrm{~g} / \mathrm{L}, \mathrm{pH} 6$ after $48 \mathrm{~h}$ at $30{ }^{\circ} \mathrm{C}$.

(a)

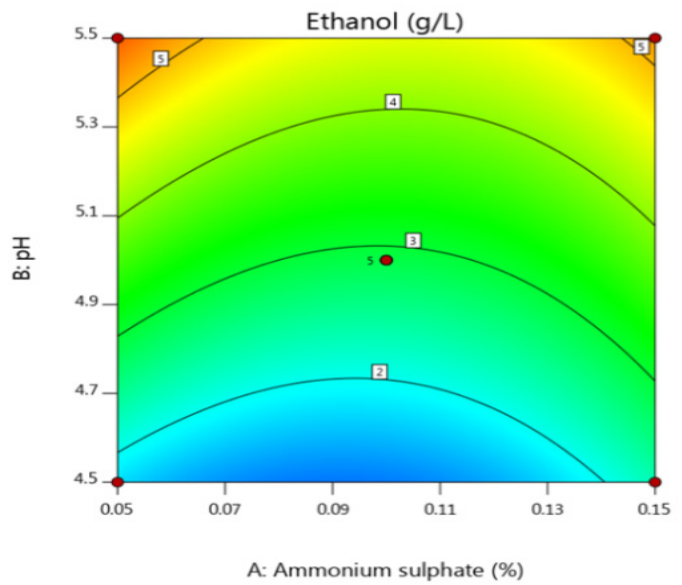

(b)

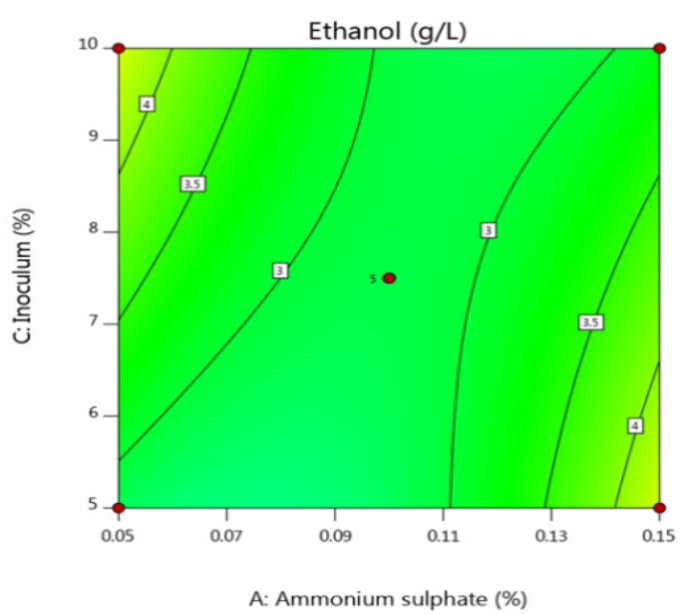

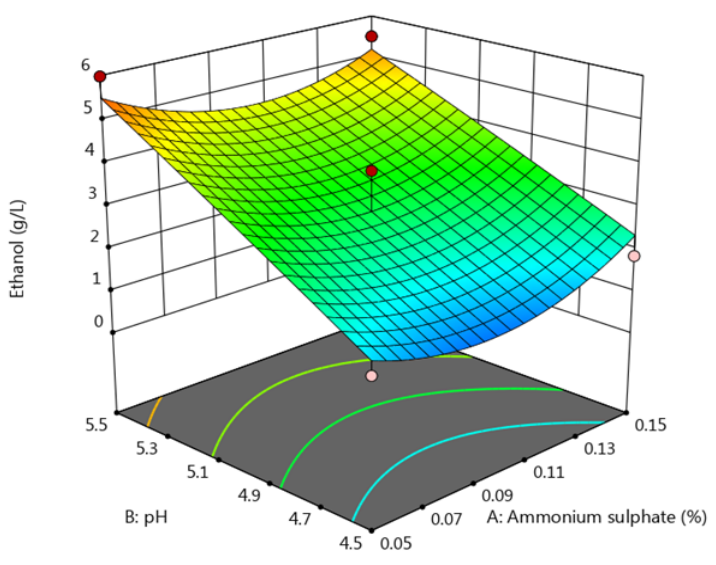

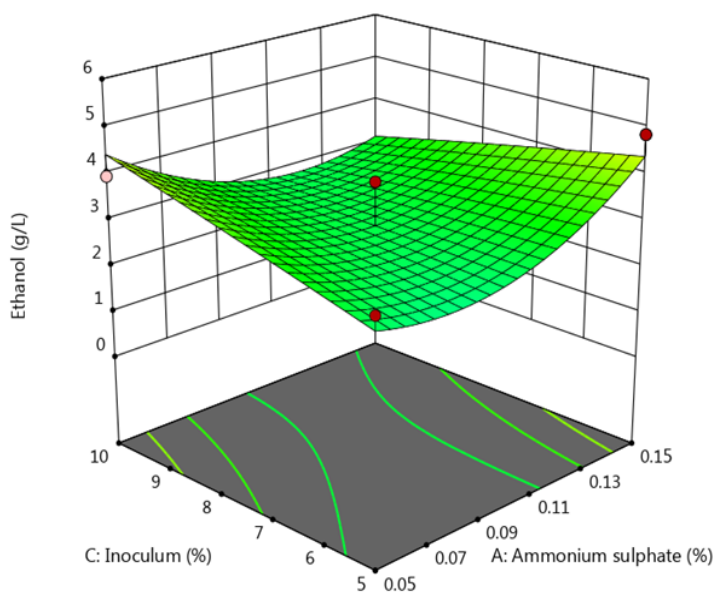



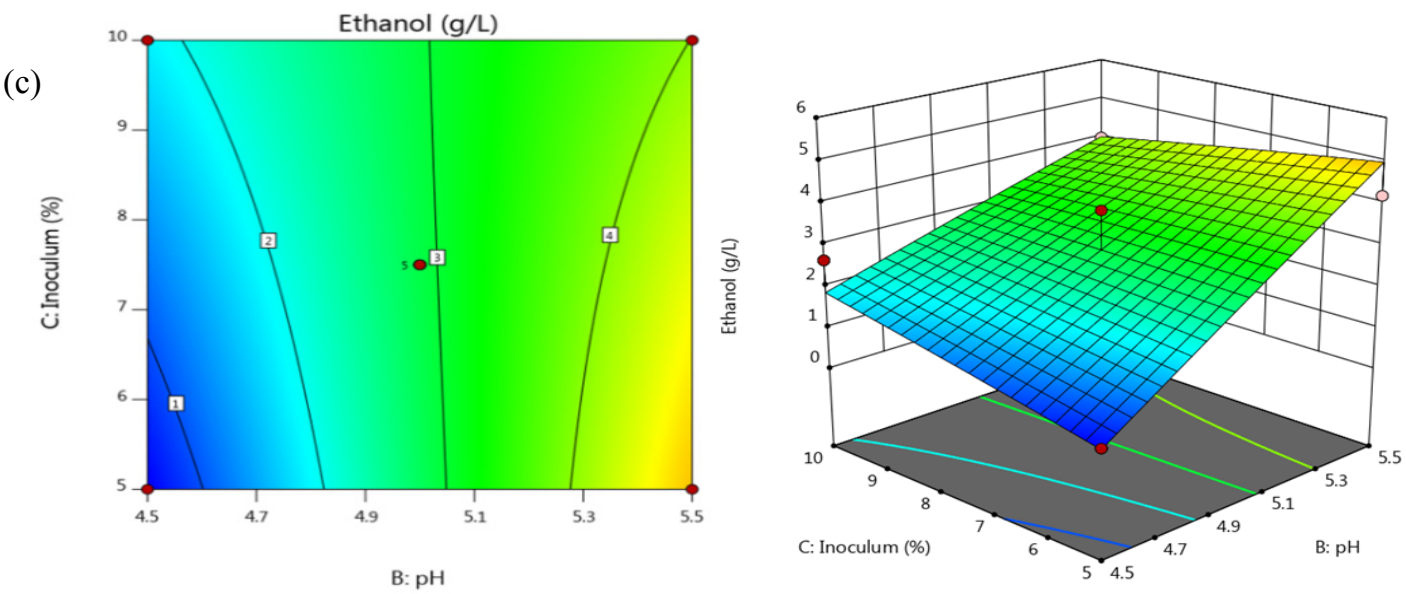

Figure 3 Response surface plot and the corresponding contour plot showing the effect of ammonium sulphate and $\mathrm{pH}(\mathrm{a})$, ammonium sulphate and inoculum (b), $\mathrm{pH}$ and inoculum (c) on ethanol production.

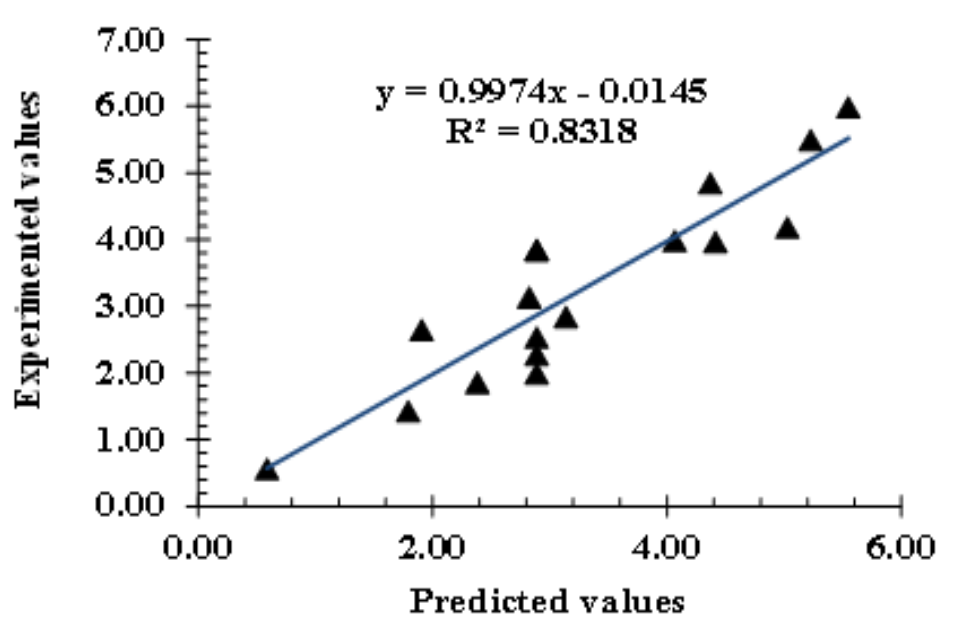

Figure 4 The predicted values and experimental values on ethanol production from the quadratic model.

The observed and model-predicted values of ethanol production after $48 \mathrm{~h}$ are shown in Figure 4. It was found that the predicted data of the response from the quadratic model agrees well with the experimental results in the range of the operating variables.

\section{Ethanol production in $9 \mathrm{~L}$ bio-fermenter}

Figure 5 demonstrates the time-course profile of ethanol production in 9 L bio-fermenter from LQSP using optimized fermentation conditions above $(0.05 \%$ of ammonium sulphate, $\mathrm{pH} 5.5$ and $5.0 \%$ of inoculum size). Ethanol yield, reducing sugar, cell dry weight, and $\mathrm{pH}$ were investigated. Ethanol yield dramatically increased in the first fermentation period of $6 \mathrm{~h}$ with $4.0 \mathrm{~g} / \mathrm{L}$ and then slightly increased until $36 \mathrm{~h}$ with $5.04 \mathrm{~g} / \mathrm{L}$. While reducing sugar dramatically decreased in $6 \mathrm{~h}$ and was constant at $36 \mathrm{~h}$ of 
http://wu.ac.th

fermentation time, yeast growth (cell dry weight) slightly decreased in $6 \mathrm{~h}$ and then was at constant the whole fermentation period.

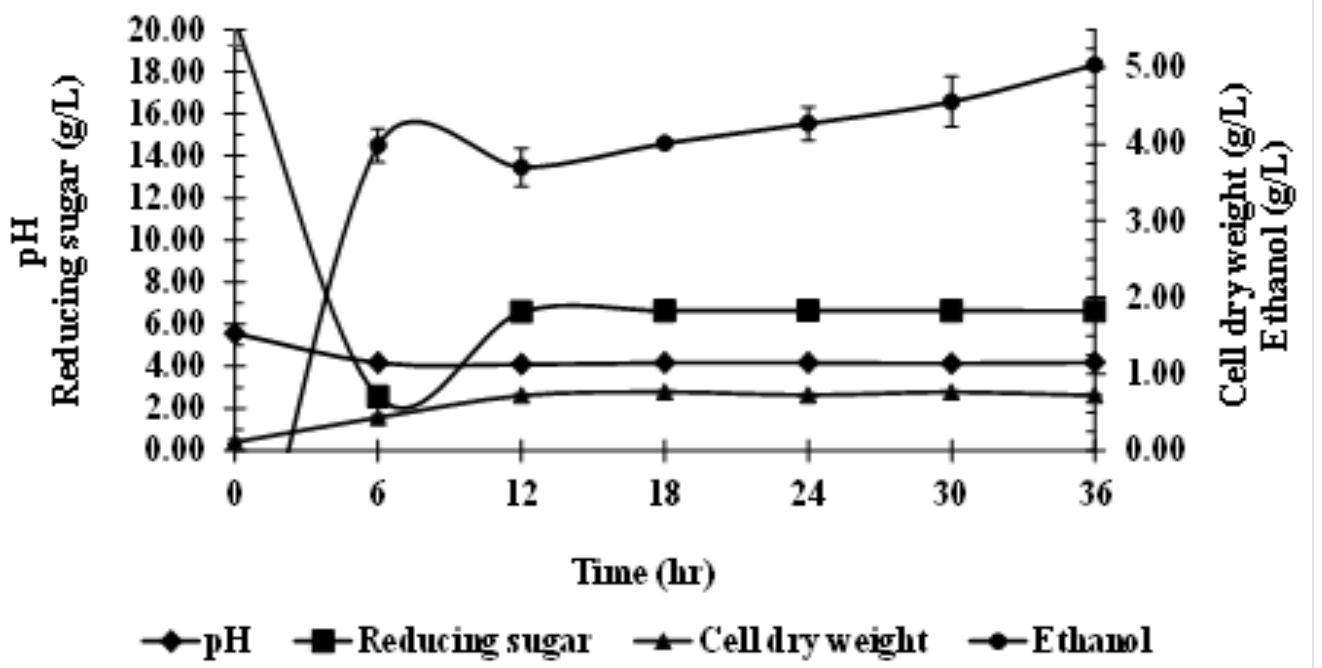

Figure 5 Time-course profile of ethanol production in 9 L bio-fermenter from LQSP under optimized conditions.

\section{Conclusions}

The results can be concluded that reducing sugar concentration would only be increased when there is an increase of LQSP. However, when acid concentration is increased, the reducing sugar decreased in acid hydrolysis with sulfuric acid. In addition, Ammonium sulphate content, $\mathrm{pH}$ and inoculum content had effected on ethanol production corresponding to the response surface methodology (RSM) using BoxBenhken design. The results were found that the optimum conditions were $0.05 \%$ of ammonium sulphate, $\mathrm{pH} 5.5$ and $5.0 \%$ of inoculum which can be produced by $5.98 \mathrm{~g} / \mathrm{L}$ of ethanol. Moreover, the maximum ethanol was $5.04 \mathrm{~g} / \mathrm{L}$ in $9 \mathrm{~L}$ fermenter using the optimum conditions. Therefore, LQSP had a potential as a substrate for ethanol production.

\section{Acknowledgement}

This work was financially supported by "graduate thesis grant from National Research Council of Thailand" and the Faculty of Agro-Industry, Rajamangala University of Technology Srivijaya, Nakhon Sri Thamarat, Thailand.

\section{References}

[1] SZ Li and C Chan-Halbrendt. Ethanol production in (the) people's republic of China: Potential and technologies. Appl. Energ. 2012; 86, 162-9.

[2] F Wirawan, CL Cheng, WC Kao, DJ Lee and JS Chang. Cellulosic ethanol production performance with SSF and SHF processes using immobilized Zymomonas mobilis. Appl. Energ. 2012; 100, 1926.

[3] S Beher, S Kar, RC Mohanty and RC Ray. Comparative study of bio-ethanol production from mahula (Madhuca latifolia L.) flowers by Saccharomyces cerevisiae cells immobilized in agar and Ca-alginate matrices. Appl. Energ. 2010; 87, 96-100.

[4] WH Duvernay, MS Chinn and GC Yencho. Hydrolysis and fermentation of sweet potatoes for production of fermentable sugars and ethanol. Ind. Crop. Prod. 2013; 42, 527-37. 
http://wu.ac.th

[5] L Putri, SE Nasrulloh and A Haris. Bioethanol production from sweet potato using combination of acid and enzymatic hydrolysis. Appl. Mech. Mater. 2011; 110, 1767-72.

[6] C Lareo, MD Ferrari, M Guigou, L Fajardo, V Larnaudie, MB Ramirez and J Martinez-Garreiro. Evaluation of sweet potato for fuel bioethanol production: Hydrolysis and fermentation. Springer Plus 2013; 2-11.

[7] LH Ziska, GB Runion, M Tomecek, SA Prior, HA Torbet and R Sicher. An evaluation of cassava, sweet potato and field corn as potential carbohydrate sources for bioethanol production in Alabama and Maryland. Biomass Bioenerg. 2009; 33, 1503-8.

[8] M Balat, H Balat and C Oz. Progress in bioethanol processing. Prog. Energ. Combust. 2008; 34, 551-73.

[9] P Kumar, DM Barrett, MJ Delwiche and P Stroeve. Methods for pretreatment of lignocellulosic biomass for efficient hydrolysis and biofuel production. Ind. Eng. Chem. Res. 2009; 48, 3713-29.

[10] QA Nguyen, MP Tucker, FA Keller and FP Eddy. Two-stage dilute-acid pretreatment of softwoods. Appl. Biochem. Biotech. 2000; 84, 561-76.

[11] N Bujang, MNM Rodhi, M Musa, F Subari, N Idris, NSM Makhtar and KHK Hamid. Effect of dilute sulfuric acid hydrolysis of coconut dregs on chemical and thermal properties. Proc. Eng. 2013; 68, 372-8.

[12] F Muhamud and I Bin. Production of Bio-Ethanol from Tapioca Starch using Saccharomyces cerevisiae. University of Malaysia Pahang, Malaysia, 2009.

[13] D Conininck, J Bouquelet, S Dumortier, V Duyme, V Verdier and I Denates. Industrial media and fermentation processes for improved growth and protease production by Tetrahymena thermophile. J. Indus. Microbiol. Biotech. 2000; 24, 285-90.

[14] MA Bezerra, RE Santelli, EP Oliveira, LS Villar and LA Escaleira. Response surface methodology (RSM) as a tool for optimization in analytical chemistry. Talanta 2008; 76, 965-77.

[15] W Horwitz and GW Latimer. Official Methods of Analysis of AOAC International. $18^{\text {th }}$ ed. AOAC International, USA, 2005, p. 856-7.

[16] GL Miller. Use of dinitrosalicylic acid reagent for determination of reducing sugar. Anal. Chem 1959; 31, 426-8.

[17] M Dubois, KA Gilles, JK Hamilton, PA Rebers and F Smith. Colormetric method for determination of sugars and related substances. Anal. Chem. 1956; 28, 350-6.

[18] M Iggland and M Mazzotti. Introduction to Chemical Engineering for Lecture 7: Flash distillation. Available at: https://www.ethz.ch/content/dam/ethz/special-interest/mavt/process-engineering/ separation-processes-laboratory-dam/documents/education/bce\%20notes/Lec7-Flash.pdf, accessed March 2018.

[19] D Kunmanotewong. Protein Separation and Comparison some Physicochemical Properties of Sweet Potato Starch. King Mongkut's Institute of Technology Ladkrabang, Thailand, 2006.

[20] OG Olatunde, OF Henshaw, AM Idowu and K Tomlins. Quality attributes of sweet potato flour as influenced by variety, pretreatment and drying method. Food Sci. Nutr. 2015; 4, 623-35.

[21] M Pratiwi, DN Faridah and HN Lioe. Structural to starch after acid hydrolysis, debranching, autoclaving-cooling cycles, and heat moisture treatment (HMT): A review. Starch 2018; 70, 1-13.

[22] LSE Putri, Nasrulloh and A Haris. Bioethanol production from sweet potato using combination of acid and enzymatic hydrolysis. Appl. Mech. Mater. 2011; 110-116, 1767-72.

[23] S Choojit, T Ruengpeerakul and C Sangwichien. Optimization of acid hydrolysis of pineapple leaf residue and bioconversion to ethanol by Saccharomyces cerevisiae. Cellulose Chem. Technol. 2018; 52, 247-57.

[24] K Yoonan, P Yowapui and J Kongkiattikajorn. Ethanol production from acid hydrolysate of cassava peels using Saccharomyces cerevisiae. KMUTT Res. Develop. J. 2007; 30, 405-17.

[25] OI Maxwell, MG Onyebuchukwu and IF Sugar. Optimization of acidic hydrolysis of sweet potato peels to produce fermentable sugar. J. Eng. 2018; 8, 20-6. 
http://wu.ac.th

[26] B Klinpratoom. 2014, Response Surface Optimization of Dilute Sulfuric Acid Hydrolysis of Cassava Stem for Lignocellulosic Ethanol Production. Master of Thesis. Khon Kaen University, Thailand.

[27 OE Onoghwarite, NVI Obiora and EA Ben. Effects of process variables on the fermentation of corn stover : A review. J. Sci. Eng. Res. 2016; 3, 279-88.

[28] RM Swain, J Mishra and H Thatoi. Bioethanol Production from sweet sotato (Ipomoea batatas L.) flour using co-culture of Trichoderma sp. and Saccharomyces cerevisiae in solid-state fermentation. Braz. Arch. Boil. Tech. 2013; 56, 171-9.

[29] A Kumar, SJ Duhan, Surekha, KS Gahlawat. Production of ethanol from tuberous plant (Sweet potato) using Saccharomyces cerevisiae MTCC-170. Afr. J. Biotech. 2014; 13, 2874-83. 